\title{
Importance of Lumpectomy Incision for Diagnosis of Carcinoma Breast and its Impact on Further Management - A Prospective Observational Study
}

\author{
Richa Sharma ${ }^{2 *}$, Dinesh Gupta ${ }^{1}$, Sanjeev Patni ${ }^{3}$ and Vijay Sharma ${ }^{4}$ \\ ${ }^{1}$ Department of Oncosurgery, Manipal Hospital, India \\ ${ }^{2}$ Department of Public Health, Jaipur National University, India \\ ${ }^{3}$ Department of Oncosurgery, Bhagwan Mahavir Cancer Hospital \& Research Centre, India \\ ${ }^{4}$ Department of Gastroenterology, Manipal Hospital, India
}

Received: December 28, 2017; Published: February 07, 2018

*Corresponding author: Richa Sharma, Department of Public Health, Jaipur National University institute of Medical research centre, Jaipur, India, Email: drrichas@gmail.com

\begin{abstract}
Introduction: Modified radical mastectomy (MRM) incision should include lumpectomy cavity and surgical scar in patients with prior lumpectomy. An incorrectly placed lumpectomy incision may not only compromise cosmetic outcome but it may even delay the adjuvant treatment.

Aim of the study: Aim of our study is to assess the effective placement of lumpectomy incision and its implications on patient management.

Patients and methods: A prospective observational study, it includes 50 patients with prior breast lumpectomy who subsequently underwent MRM at our center from January 2009 to June 2010. Lumpectomy scars were divided into four categories based on extent of modification required in placement of incision for mastectomy to achieve primary closure after MRM.

Results: Out of 50, 24 (48\%) patients had scars which were easily incorporated in Stewart incision. In 15 (30\%) patients, flaps were under tension with Stewart incision. In 9 (18\%) patients, MRM incision had to be modified to Orr incision or other modifications to achieve primary closure. Five (10\%) patients had minor/major wound complications thereby delaying adjuvant treatment. One (2\%) patient required skin graft and another required latissimus dorsi flap for closure.

Conclusion: Based on above findings, it is highly recommended that lumpectomy should only be done if diagnosis is not possible after FNAC or core needle biopsy. It should be done by the surgeon who shall be subsequently performing the definitive surgical treatment.

Keywords: Lumpectomy incision; Modified radical mastectomy; Stewart incision; Orr incision; Primary closure; Cosmesis; Breast conserving surgery
\end{abstract}

\section{Introduction}

Benign breast disease is the most common cause of breast problems; up to $30 \%$ of women will suffer from a benign breast disorder requiring treatment at some time in their lives. The most common symptoms are pain, lumpiness or a lump. The aim of treatment is to exclude cancer and, once this has been done, to treat any remaining symptoms [1]. Also, breast cancer is a major public health problem for women throughout the world. In United States, breast cancer remains the most frequent cancer in women and the second most frequent cause of cancer death [2]. As per IARC (international agency for research in cancer, 2008) data, breast cancer accounts for 1383 thousand cases worldwide with 458 thousand deaths per year. In India, it accounts for $22.9 \%$ of all cancers with $11.9 \%$ mortality. The women with breast lump may have to undergo evaluation (to exclude malignancy in benign conditions, to prove malignancy in suspicious conditions).

The available diagnostic techniques are fine needle aspiration cytology (FNAC), core needle biopsy and excisional biopsy. Both FNAC and core needle biopsy are office procedures. FNAC is easily performed, but requires a trained cytopathologist for accurate specimen interpretation. The sensitivity of FNAC ranges from $80 \%$ to $95 \%$, and false-positive aspirates are seen in fewer than $1 \%$ of cases in most series. False-negative results are seen in $4 \%$ to $10 \%$ of cases and are most common in fibrotic or well-differentiated tumors $[3,4]$. A significant change in breast surgery was the shift from open surgical biopsy to image-guided core needle biopsy (for the diagnosis of breast abnormalities). 
The current literature supports the superiority of an image-guided core needle biopsy over an open surgical biopsy for the clear majority of patients with a breast abnormality [5]. This technology has decreased the frequency of operative procedures, allowed for tailored care of proven malignancies, and improved the accuracy of definitive surgical management of breast cancer [6]. In developed countries, most of cases are diagnosed by fine needle aspiration cytology (FNAC) and core needle biopsy and so patients presenting for modified radical mastectomy (MRM) after lumpectomy are fewer in number. But in developing countries, many cases are referred to cancer Centre with a diagnosis of carcinoma breast after lumpectomy has been done at primary Centre.

While doing MRM in the patients with prior lumpectomy, the most important point to be considered is inclusion of lumpectomy scar and lumpectomy cavity in MRM incision. The type of incision used varies based on the exact location of the tumor and the size of the breast, but it should always include the nipple-areola complex and the biopsy site and allow for access to the axilla for possible axillary nodal dissection $[7,8]$. This can pose difficulty in patients who have incorrectly placed lumpectomy scars. The most preferred incision for MRM is transverse elliptical-Stewart incision. Though Orr incision is an effective alternative, but the incision lines are against the natural lines of tension, Langer lines. Moreover, it can pose difficulty in hiding the scar when wearing a sleeveless or shoulder less dress. Also it can cause fibrosis at the anterior axillary fold leading to difficulty in overhead abduction. Over the years, we have come across many cases of breast lumpectomy scars in which we faced difficulty in incorporating them into MRM incisions. This prompted us to study the importance of lumpectomy scar and its implication on further management.

\section{Patients and Methods}

This study was designed to assess the effective placement of lumpectomy incision in patients undergoing MRM after breast lumpectomy and its implication on patient management.

Study design - Prospective observational study.

\section{Inclusion criteria}

1. Female patients, of all ages were included.

2. Patients who had undergone lumpectomy for lump breast outside and then presented to us for further management with a diagnosis of carcinoma breast.

3. All the patients subsequently underwent Modified radical mastectomy at our Centre as a definitive management (between January 2009 to June 2010).

\section{Exclusion criteria}

Patients with lumpectomy scar who subsequently underwent BCS were excluded. Based on the effective placement of lumpectomy scar and the ease with which it could be included in the MRM incisions (with modifications of incision if required), we classified the scars into 4 categories- Operating surgeon was asked to categorize the scar into one of four categories. Data was evaluated on the basis of adequacy of scar and how it affected the placement of incision for MRM. Any complication or delay in adjuvant treatment was noted.

\section{Results}

259 patients underwent MRM in our institute during the period of January 2009 to June 2010. Out of these 259 cases, $50(19.3 \%)$ cases presented with a lumpectomy done outside. Age of patients ranged from 28 to 75 years (mean 45 years). The length of breast scar ranged from 3 to $14 \mathrm{~cm}$. T stage of all the patients could not be assessed because histopathology reports of lumpectomy specimen from outside were not informative about the size of tumor in $11 / 50$ patients and specimen could not be procured for review in these cases.

$24 / 50$ (48\%) cases were placed in category one by operating surgeon. $15 / 50(30 \%)$ cases were placed in category two and $9 / 50(18 \%)$ cases were placed in category three. $2 / 50(4 \%)$ cases were placed in category four. Out of a total of 50 cases presenting with a previous lumpectomy, 24 (48\%) patients had their lumpectomy scar placed appropriately to be included in Stewart incision, while in 15 cases transverse incision could be placed taking risk of complications related to flap. Out of the 15 (30\%) patients in category two, five patients had major/minor skin flap necrosis and in these patients adjuvant treatment was delayed for more than 6 weeks post-operative.

In $9(18 \%)$ patients in category III, it wasn't possible to go ahead with Stewart incision and incision was modified to Orr incision or other modifications of incisions which compromised cosmesis and caused functional disability due to scarring at anterior axillary fold. One (2\%) patient in category IV required skin grafting while one (2\%) patient required latissimus dorsi flap. In the patient with skin graft, adjuvant treatment (chemotherapy/ radiotherapy) was delayed because of partial graft rejection. Some of the wrongly placed scars were-vertical scar in upper outer quadrant ( 2 cases), scar extending across whole length of breast (extending in more than two quadrants) in 6 cases, oblique upwards radial scar starting from nipple and extending to upper outer quadrants in 2 cases, vertical incision extending upwards from nipple-areola complex in 2 cases, vertical scar high up in upper inner quadrant in one case (Figure $1 \& 2)$. 


\section{Open Access Journal of Surgery}

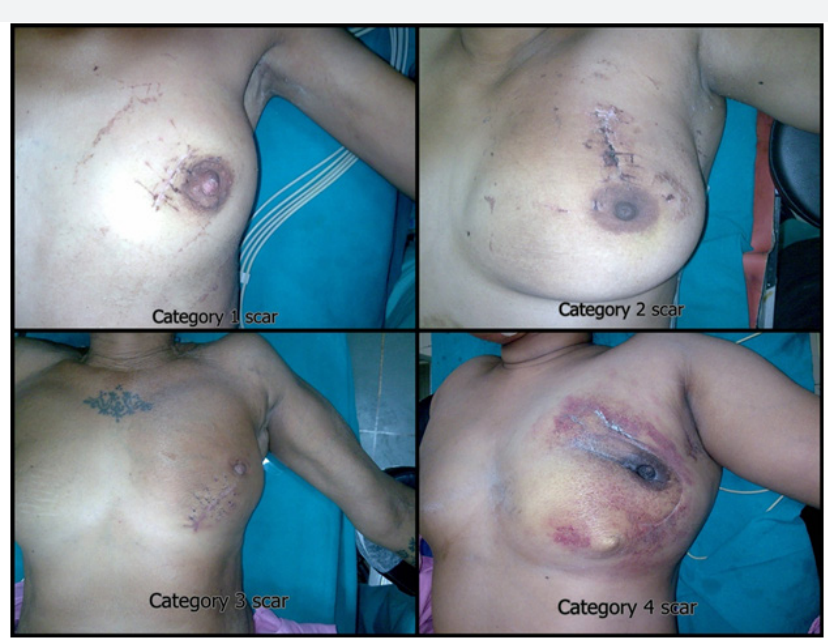

Figure 1: Few of the wrongly placed lumpectomy scars.

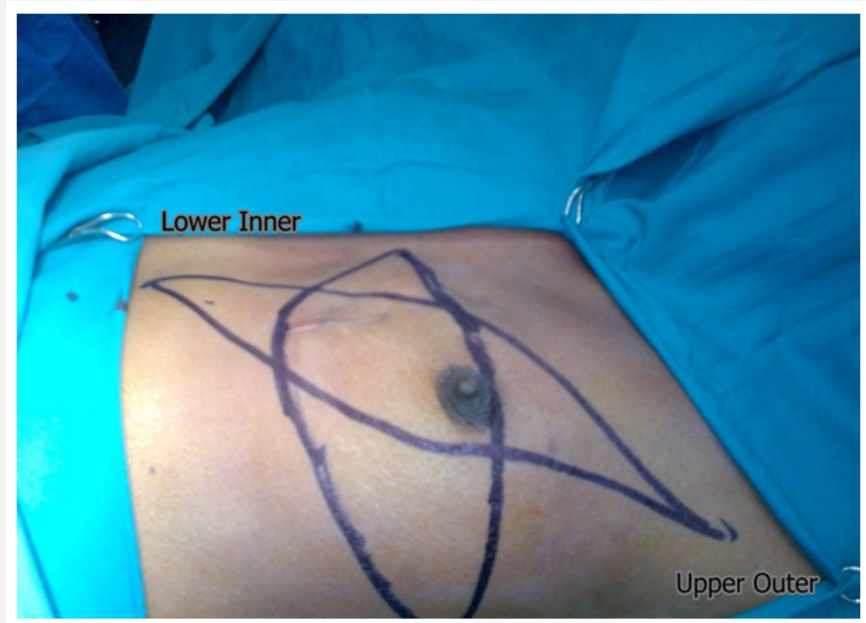

Figure 2: An Orr incision had to be placed instead of Stewart incision because of vertical scar in lower inner quadrant.

\section{Discussion}

A recommendation for placement of incision for breast lumpectomy-Excision biopsy refers to the complete extirpation of a breast mass. The objective is to remove the entire breast mass with a minimal amount of normal tissue around it. An excisional biopsy may sometimes be needed to establish a diagnosis. It is important to remember that natural lines of skin tension, known as Langer lines, extend outwards circumferentially from the nipple-areola complex. Therefore, at or above the level of the nipple, when performing an excisional biopsy, the incision should never be placed perpendicular to the natural lines of skin tension. Rather, the incision should follow these lines and be placed in a semicircular or peri-areolar fashion [9]. Below the nipple, the incision lines may be placed radially or along the inframammary fold.

An excisional biopsy is performed with a curvilinear incision along a natural skin crease line (line of Langer). If the tumor is close to the skin, an elliptical incision is made, and the skin within the ellipse is included with the specimen. Large incisions placed in other than these orientations can deform the breast and result in poor cosmesis [6]. The surgeon should take time to draw the incision, as well as the site of the lesion, directly onto the patient. The size of the incision should be kept to the minimum size that still allows adequate retrieval of the targeted lesion as well as palpation and visualization of the cavity for hemostasis. Usually, this is not more than 3 to $4 \mathrm{~cm}$ in length [6] (Figure 3). 


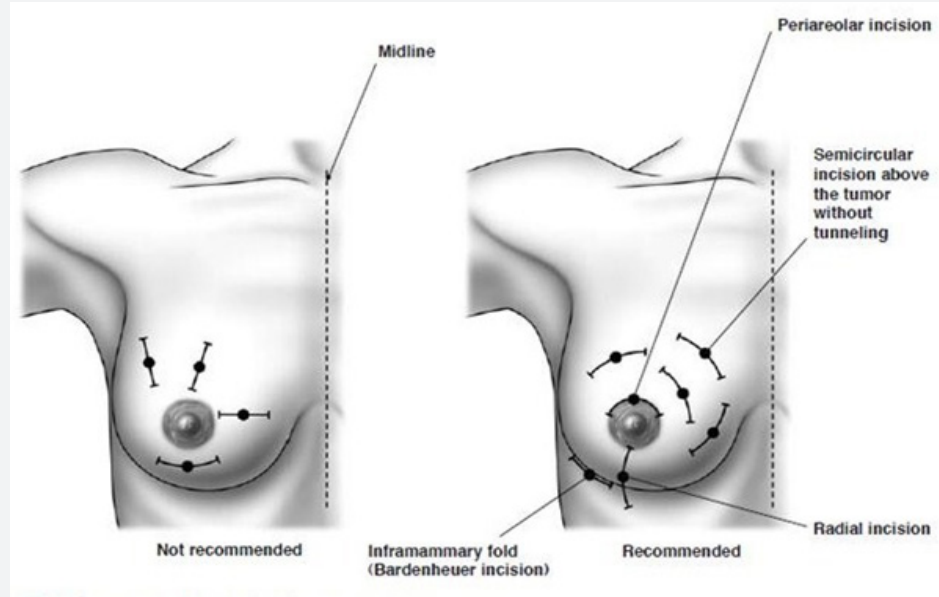

Figure 3: Recommended incision lines for excisional biopsy $[9,10]$.

When excisional biopsy is performed for diagnosis, a small margin of grossly normal breast should be excised around the tumor, orienting sutures should be placed, and the specimen should be linked to allow margin evaluation. This procedure allows an assessment of the completeness of the excision if carcinoma is found, sparing patients with negative margins further breast surgery and allowing re-excision to be limited to the involved margin surface(s) [2].

\section{Implications of unplanned scar}

a) Skin flaps in category two scars may be under tension, so they have increased chances of skin margin/skin flap necrosis.

b) Sometimes for incorporating a breast scar into MRM incision, Orr incision or other modifications may be required which are inferior in cosmesis to Stewart incision. Also Orr incision restricts overhead abduction leading to functional problem. c) Adjuvant treatment may be delayed in patients requiring SSG/Flap for closure (because of morbidity of SSG/Flap).

d) Option of breast conservative surgery may not be offered because of unplanned lumpectomy scar and unknown status of cut margins.

e) Higher cost of treatment because of additional procedure performed (SSG/Flap).

f) Secondary reconstruction of breast in form of implants and flaps (especially where skin expansion is required) becomes difficult due to excessive loss of skin in unplanned lumpectomy scars (Table 1 ).

g) If Orr incision is used for primary surgery, it would become more prominent and visible after secondary reconstruction.

Table 1: Classification of lumpectomy scars.

\begin{tabular}{|c|c|}
\hline Category 1 & No modification of MRM incision required, primary closure easily possible with Stewart \\
incision.
\end{tabular}

Breast surgery has come a long way from Halsted radical mastectomy to BCS and neoplastic surgeries. Breast surgeries have always been related to the cosmesis and females are apprehensive about it more often than not. Cosmetic appearance is of utmost importance while planning MRM incisions. Till date transverse elliptical incision has been regarded as the most cosmetic incision. Obliquely placed incisions compromises appearance as they are visible outside the clothes and are not acceptable to many females. Transverse incision kept under tension because of unplanned lumpectomy scars can lead to skin flap necrosis, resulting in delayed recovery. 
This delay translates into delayed adjuvant treatment. Adjuvant treatment should start within 4-6 weeks of surgery [11-13]. This delay can increase chances of relapse. Even for benign conditions, incision should be properly and cosmetically placed and should be planned as per prescribed norms. As far as possible, FNAC/ core needle biopsy should be done for diagnosis and lumpectomy should be avoided. If required lumpectomy should be planned in such a way that it can be incorporated easily in transversely placed incision for MRM. Also it is better to do lumpectomy with adequate margins and proper orientation of specimen so that breast conservation can be offered if feasible. It is always better that such procedure be done at a high volume Centre and by the surgeon undertaking the definitive treatment.

\section{References}

1. Williams NS, Bulstrode CJK, O'connell PR (2008) The Breast. In: Williams NS. Bailey \& Love' short practice of surgery, $\left(25^{\text {th }}\right.$ edn $)$ Edward Arnold Publishers Ltd, London pp: 827-848.

2. Harold JB, Jay R H, Monica M (2008) Malignant tumors of the breast. In: De Vita V T Cancer: Principles \& Practice of Oncology, $\left(8^{\text {th }}\right.$ edn), Lippincott Williams \& Wilkins, Philadelphia, USA, pp: 1606-1654.

3. Hammond S, Keyhani Rofagha S, O’Toole RV (1987) Statistical analysis of fine needle aspiration cytology of the breast. A review of 678 cases plus 4,265 cases from the literature. Acta Cytol 31(3): 276-280.

4. Aziz M, Ahmad N, Zahid J, Faizullah, Aziz M (2004) Comparison of FNAC and open biopsy in palpable breast lumps. J Coll Physicians Surg Pak 14: 654-656.

5. Smyczek Gargya B, Krainick U, Müller Schimpfle M, Mielke G, Mayer R, et al. (2002) Large-core needle biopsy for diagnosis and treatment of breast lesions. Arch Gynecol Obstet 266(4): 198-200.

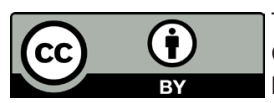

This work is licensed under Creative Commons Attribution 4.0 Licens DOI: 10.19080/OAJS.2018.08.555727
6. Tafra L, Cheng Z (2009) Breast biopsy and breast conserving surgical techniques. In: Evans (Ed.), \

7. Surgical pitfalls: prevention and management, Saunders, Philadelphia, USA 455-463.

8. Toth BA, Forley BG, Calabria R (1999) Retrospective Study of the SkinSparing Mastectomy in Breast Reconstruction. Plast Reconstr Surg 104(1): 77-84.

9. Toth BA, Lappert P (1991) Modified skin incisions for mastectomy: the need for plastic surgical input in preoperative planning. Plast Reconstr Surg 87(6): 1048-1053.

10. Jatoi I, Kaufman M, Petit JY (2006) Biopsy procedures. In: Ismail Jatoi. Atlas of breast surgery, ( $1^{\text {st }}$ edn), Springer, New York, p: 55-60.

11. Brunicardi FC, Anderson DK, Billar TR (2010) The Breast. In: Brunicardi FC. Schwartz's Principles of Surgery, $\left(9^{\text {th }}\right.$ edn), The McGrawHill Companies, USA, pp: 423-474.

12. Pronzato P, Campora E, Amoroso D, Bertelli G, Botto F, et al. (1989) Impact of administration related factors on outcome of adjuvant chemotherapy for primary breast cancer. Am J Clin Oncol 12(6): 481485 .

13. Colleoni M, Bonetti M, Coates AS, Castiglione Gertsch M, Gelber RD, et al. (2000) Early start of adjuvant chemotherapy may improve treatment outcome for premenopausal breast cancer patients with tumors not expressing estrogen receptors. The International Breast Cancer Study Group. J Clin Oncol 18(3): 584-590.

14. Kerbrat P, Roche H, Fumoleau P, Bonneterre J, Romestaing P, et al. (2005) Does time interval between surgery and adjuvant chemotherapy initiation modify treatment efficacy in operable, breast cancer patients? French Adjuvant Study Group (FASG) Results. J Clin Oncol 23: 660.

Your next submission with Juniper Publishers will reach you the below assets

- Quality Editorial service

- Swift Peer Review

- Reprints availability

- E-prints Service

- Manuscript Podcast for convenient understanding

- Global attainment for your research

- Manuscript accessibility in different formats

( Pdf, E-pub, Full Text, Audio)

- Unceasing customer service

Track the below URL for one-step submission https://juniperpublishers.com/online-submission.php 